\title{
Optimizing efficiencies in biosecurity surveillance and monitoring: testing colour and multi-lure traps on tomato potato psyllid, other plant-lice (Psylloidea) and stinkbugs (Pentatomoidea)
}

Melinda Moir ( $\square$ melinda.moir@dpird.wa.gov.au )

Government of Western Australia Department of Primary Industries and Regional Development https://orcid.org/0000-0002-6765-5162

\section{Louise Croeser}

Government of Western Australia Department of Primary Industries and Regional Development Don Telfer

Government of Western Australia Department of Primary Industries and Regional Development Christopher Fenner

Government of Western Australia Department of Primary Industries and Regional Development Rosalie McCauley Government of Western Australia Department of Primary Industries and Regional Development

\section{Research Article}

Keywords: Bactericera cockerelli, biosecurity surveillance, Diaphorina citri, insect vectors, pest insect species, trap design

Posted Date: November 30th, 2021

DOI: https://doi.org/10.21203/rs.3.rs-853713/v1

License: (c) (i) This work is licensed under a Creative Commons Attribution 4.0 International License. Read Full License 


\section{Abstract}

Cost efficiency in biosecurity surveillance is vital, and the ability to survey for multiple pest species using just one trap therefore highly appealing. The Psylloidea, or plantlice, contain significant horticultural pest species that act as vectors for a number of deleterious plant bacteriums. We examine the efficacy of using two different coloured sticky traps, and two lure types on the general Psylloidea and Pentatomoidea fauna, and a target extant pest psyllid; tomato potato psyllid (TPP) Bactericera cockerelli (Šulc). Specifically, we test the effect of lure (no lure, Asian citrus psyllid ACP lure, brown marmorated stink bug BMSB lure, combined lures), sticky trap color (green vs yellow), and sentinel plant (tomato vs citrus) on psyllid and stink bug species in 104 urban backyards across Perth, Australia. We found that tomato sentinel host plants and green traps significantly increased the capture rate of TPP, but that all lures decreased the capture of TPP. Green traps also increased the capture rate of all other Psylloidea. Although BMSB lures reduced TPP capture, these lures increased abundances of other Psylloidea and the pest stinkbug Plautia affinis (Dallas) on traps. Thus, our experiment demonstrates that increased efficiencies can be gained with combination traps and lures for particular groups, provided that they have been tested on focal organisms in the first instance, as reactions to non-target lures are unpredictable and species specific.

\section{Key Message}

- Constructing multi-species trapping systems will optimize biosecurity surveillance efforts

- Lures have unpredictable capture efficacy on different Psylloidea

- Trap colour was important for Psylloidea, but not Pentatomoidea

- Multi-lure trap systems must be trialled on secondary target pests before being employed

\section{Introduction}

Biosecurity surveillance is an ever-escalating cost due to increased global travel, free trade agreements, and open markets (Cope et al., 2019); (Meurisse et al., 2019). Accumulation rates of introduced taxa are not slowing (Seebens et al., 2017), suggesting current surveillance and control methods are only partially effective in many regions (Meurisse et al., 2019). Targeted risk analysis and surveillance for invasive plant pests increases the likelihood of early detection and eradication, lessening the potential of establishment and spread, thus reducing the impact of these pests (e.g., (Cope et al., 2019). In recognition of the importance of rigorous surveillance for plant pests, the European Food Safety Authority provided guidelines for designing risk-based surveys of plant pests ( European Food Safety Authority, 2020), and delivered RiBESS, a tool to calculate the sample size needed to substantiate absence of a pest and survey sensitivity (European Food Safety Authority, 2012). This tool provides more impetus to jurisdictions to conduct cost-effective and statistically sound surveillance for plant pests. Given the cost of surveillance, the rigour required and the increasing numbers of invasive pests able to exploit global movement, opportunities to increase the surveillance 'bang for the buck' should be embraced. Examples of such 
opportunities include optimising efforts in high-risk pathways and value-adding to surveillance efforts by targeting more than one pest species at each trapping site. Combining the monitoring of established nonnative insect pests with targeted biosecurity surveillance of exotic pests is attractive but is not always employed because of the vast array of insect species with different ecological and biological characteristics, taxonomic challenges, difference in trap types and finite resources (Brockerhoff et al., 2013).

The Psylloidea, or plantlice, contain significant horticultural pest species including Asian citrus psyllid Diaphorina citri Kuwayama, African citrus psyllid Trioza erytreae Del Guerci, tomato potato psyllid Bactericera cockerelli (Šulc, 1909), and carrot psyllids, particularly Bactericera trigonica Hodkinson and Dyspersa apicalis (Foerster) (Burckhardt, 1994). It is not the insect feeding per se that causes the most damage, but their ability to act as vectors for some devastating plant bacteriums, particularly Candidatus Liberibacter spp (e.g., (Catling, 1970); (Munyaneza et al., 2011); (Antolinez et al., 2017)). Sticky traps have been used as the most effective, cost-efficient method for capturing most of these pests and are thus also promoted for biosecurity purposes (e.g., tomato potato psyllid: (Yen et al., 2013), (Hodge et al., 2019); Asian citrus psyllid: (Hall et al., 2010); carrot psyllids: (Burckhardt \& Freuler, 2000); apple psyllids:

(Miñarro et al., 2016). Traps are particularly effective if an attractant is added, for example, if placed near a host plant of target species, which are also known as sentinel plants (Mansfield et al., 2019). Attractant sampling has evolved further, with lures now available for some species like Asian citrus psyllid (Zanardi et al., 2019). Although lures increase the likelihood of capturing target species, the impact of trap efficacy for other species is predominantly unknown. Lures may result in interspecific repellency; actively dissuading other pest species from approaching the trap. Regardless, multispecies trapping using a variety of attractants on the same trap has been tested for fruitflies (Thomas et al., 2001); (Stringer et al., 2019), moths (Brockerhoff et al., 2013), woodboring beetles (Wong et al., 2012); (Hoch et al., 2020) and pests within different insect orders (Baroffio et al., 2018); (Chase et al., 2018).

We aim to determine whether a psyllid species-specific lure (Asian citrus psyllid), and a non-psyllid lure (brown marmorated stink bug) dissuaded a target organism, tomato potato psyllid (Bactericera cockerelli). Additionally, Asian citrus psyllid specific yellow-green sticky traps (herein called 'green' traps) were tested to determine the capture rate of TPP compared to standard yellow sticky traps. Finally, we question the efficacy of the lures and coloured sticky traps across other psyllids including many native species (Psylloidea) and the stinkbug fauna (Pentatomoidea) to discern patterns. We conducted these trials in an urban setting as major entry points such as ports and airports in urban areas have been shown to be high risk pathways for incursions of exotic species (Colunga-Garcia et al., 2013); (Hoch et al., 2020). Indeed, TPP established in metropolitan areas initially before spreading across rural regions in New Zealand (Teulon et al., 2009), (Thomas et al., 2011) and Western Australia (Department of Agriculture and Water Resources 2017).

\section{Methods And Materials}


Tomato potato psyllid (TPP) (Hemiptera: Triozidae) is one of the world's most destructive horticultural pests (Teulon et al., 2009); (Butler \& Trumble, 2012); (Greenway \& Rondon, 2018). The damage is attributable to the psyllid feeding on host plants, as well as a phloem-limited, unculturable bacterium Candidatus Liberibacter solanacearum (CLso) that TPP is a vector for, and which causes a disease called 'psyllid yellows' or 'zebra chip' (Munyaneza et al., 2007). The psyllid's host range includes many Solanaceous plants such as tomato, capsicum, chilli, eggplant, and tobacco, plus some other families such as Convolvulaceae which includes sweet potato (for a full list see CABI 2021).

In February 2017 TPP was discovered in an inner suburban region of Perth, Western Australia. This was the first mainland Australian incursion, after TPP established in New Zealand in 2006 (Teulon et al., 2009) and on the Australian territory of Norfolk Island in 2015 (Walker et al., 2015). As TPP was deemed unfeasible to eradicate from Western Australia, surveillance focused on detecting the presence of CLso. Monitoring occurs in Perth's autumn (March) and spring (October) growing seasons, and began in March 2017. Fortunately, the associated bacterium has not been detected, however, TPP has been detected in Albany in the south of Western Australia, Esperance in the east, and north to Geraldton and Carnarvon, presumably through accidental human-mediated dispersal.

\section{Experimental Design}

Adopt-a-trappers from within the greater Perth metropolitan region were recruited to host traps over a 4week period in October 2020. Trappers were selected from previous surveillance for CLso, which demonstrated that they had TPP in their gardens in the previous two years. Trappers were given a tomato plant and a native citrus plant (Murraya sp.) as sentinel plants for TPP and ACP, respectively. Seven trappers used their own established citrus trees (lemon or orange) instead of the offered Murraya plant. Trappers were randomly assigned traps with one of the below designs (Table 1).

Table 1

Number of trappers with different coloured traps, lure types and sentinel plants. Note that all trappers had a minimum of two yellow traps, a Tomato and Murraya sentinel plants.

\begin{tabular}{|llllll|}
\hline Plant & sticky trap & Lures* & & \\
\hline & & Control & BMSB & ACP & BMSB \& ACP \\
\hline Tomato & Yellow & 29 & 24 & 27 & 21 \\
\hline Murraya sp. & Yellow & 29 & 24 & 27 & 21 \\
\hline Tomato & Green & 4 & 6 & 6 & 9 \\
\hline *Lures were only attached to the yellow sticky trap near tomato
\end{tabular}

Participants were each allocated a minimum of eight yellow sticky traps (four with a white dot, four with a red dot), two trap cages, 16 barcodes, eight trap protectors (clear plastic sleeves), four return post 
envelopes, four trap return sheets and a lure. Lured traps were yellow sticky traps with red dots, with the lure attached to the cage of the trap, and placed near the tomato plant on trapper's properties (Fig. 1). The control lure was a square of felt glued on to the cage. Yellow traps with the white dot were placed in their cage near the Murraya plant without any lure, and approximately $2 \mathrm{~m}$ from the tomato plant (Fig. 1). A subset of trappers were given a third trap and cage, with two 'green' sticky traps, to be placed near their tomato plant. Volunteers were asked to submit a report and photos using MyPestGuide ${ }^{\text {TM }}$ Reporter (see https://www.agric.wa.gov.au/pests-weeds-diseases/mypestguide ) in the first week of trapping to report their sticky trap locations. Each week the sticky traps were collected and replaced. Used sticky traps were placed in protective plastic sleeves with a barcode identifier. Traps were returned in a prepaid envelope along with a trap return sheet that also included a duplicate barcode to ensure that traps could be linked to location and date.

Once returned, the traps were triaged, assigned a lab identification number and entered in the Sample Manager (Version 12.2; Thermo Fisher Scientific, 2019) database. We used Leica M80 dissecting microscopes to identify and count insects on the traps. Pentatomoidea were identified to species level, while Psylloidea were classified as follows "TPP", "Other Triozidae" and "Other Psylloidea". In addition, we scanned the traps for Pentatomoidea and Psylloidea exotic to Western Australia. Results were recorded on the individual lab sheet for that trap, which included its unique identification number, and data was subsequently entered into the database. When TPP were found, specimens were cut from the trap using a scalpel and cleared of adhesive material using household-grade orange oil and Decon 90, then sent for PCR testing to monitor for any presence of the exotic bacterium CLso. Weekly emails were sent to adopt-

a-trappers informing them of their TPP count and the presence of any concerning species, as well as their MyPestGuide reports replied to with any interesting finds. The traps were stored in a refrigerator and associated paperwork filed.

\section{Data Analysis}

Logistic regression models (family "Poisson") were used to analyse the data in RStudio ( $v$ 1.3.1093), R (R Development Core Team 2020, v 4.0.3). The model for evaluating the effect of trap type on the number of insects trapped, had trap type as predictor variable and number of TPP, other Triozidae or Other Psylloidea as response variables. The second model evaluated the effect of lure type on the number of insects trapped and had lure type as predictor variable and number of TPP, other Triozidae, Other Psylloidea or Pentatomoidea as response variables. Model residuals were tested for the assumptions and no issues were detected. Post hoc validations were done, using Tukey's HSD (honest significant difference) test for multiple comparisons. Specific R packages used were 'ggplot2', 'ggthemes', 'MASS', 'reshape2', 'tidyverse', 'RColorBrewer', 'emmeans', 'rcompanion', 'performance', 'multcompView', 'pscl', 'FSA'.

\section{Results}

In total, 9,180 insects were identified from 820 traps, set at 104 adopt-a-trapper's households. The number of traps assessed were less than the maximum (882) because some trappers were only recruited for two 
weeks, other trappers did not return the full complement of traps, and quality control removed data when a trapper's lure set up was determined to be less than optimal (e.g., lure wrappers not removed, lures placed on the wrong traps, plants spaced too far apart) for the first week through assessing reports on the MyPestGuide app. The insects consisted of 4,864 TPP, 868 other Triozidae, 3,415 other Psylloidea and 31 Pentatomoidea (stinkbugs). No exotic Psylloidea or Pentatomoidea were detected, including Asian citrus psyllid or brown marmorated stinkbug, despite lures of these species present on 72 properties.

\section{TPP}

TPP were collected at 86 households ( $82 \%$ of properties). TPP were attracted to the green sticky traps in significantly higher abundance at a mean of 16.46 TPP per trap than the yellow sticky traps (9.99 TPP per trap) (Fig. 2A). Unsurprisingly, yellow sticky traps placed with a citrus sentinel plant attracted far fewer TPP at 2.89 per trap (Fig. 2A). When lures were added to traps, these reduced the number of TPP captured significantly, regardless of whether the lure was BMSB (to 4.32 TPP individuals), ACP (6.17 TPP), or a combination (6.58 TPP), however, BMSB lures were the most dissuasive (Fig. 2D).

There appeared to be an interaction with time, in that the impact of ACP lures on TPP slightly decreased after week 1 (Fig. 2G), although this interaction wasn't significant. Control traps indicated a peak in TPP numbers in week 2. In contrast, both lures combined showed no difference in TPP capture over time, maintaining low levels, while BMSB lures continued to dissuade TPP into week 4 (Fig. 2G). However, there was no significant interaction with time overall, likely due to the large weekly fluctuations of the control, particularly in week 2 .

\section{Other Triozidae}

Despite being in the same family as TPP, there were far fewer other Triozidae represented on the traps overall (Fig. 2B) and 25\% of properties didn't record any (26 households). Although there were no clear patterns of preference with regards to lures (Fig. 2E), there was a general reduction of individuals captured over time, by approximately $50 \%$ for the control, ACP and BMSB lures (Fig. 2E). A peak in triozid abundance was noted in week 2 for ACP and both lures combined, while it occurred in week 3 for the control traps (Fig. 2H).

\section{Other Psylloidea}

Other Psylloidea were found at every property except two (98\% had other Psylloidea). They were also attracted to the green sticky traps in significantly higher abundance at a mean of 9.98 per trap than the yellow sticky traps (3.61 per trap) (Fig. 2C). In contrast to TPP, yellow sticky traps placed with a citrus sentinel plant attracted similar abundance of psyllids as the tomato traps at 3.71 per trap. When lures were added to traps, ACP had no impact (3.01 per trap), but the BMSB lure had a positive effect on the Psylloidea, increasing capture rates significantly to 5.94 per trap (Fig. 2F). However, when ACP lures were added in combination, this interfered with BMSB lures, and reduced the efficacy back to control levels of 3.82 individuals per trap (Fig. 2F). The attractiveness of BMSB lures on other psyllids significantly 
decreased over time $(P<0.05)$ until reaching the levels of all other traps by week 4 (Fig. 2I). Control traps indicated a peak in psyllid numbers in week 3 . In contrast, ACP and both lures combined showed little difference in psyllid capture over time, maintaining lower and not displaying the peak in week 3 of the control traps levels (Fig. 2I).

\section{Stinkbugs}

Outside of the lure experiment, and for surveillance of the bacterium CLso vectored by TPP, 447 yellow traps were placed near tomato but no stinkbugs were captured on any of these. Only $18 \%$ of lure experiment trappers captured stinkbugs (19 households). Of these households, very few stinkbugs were captured near citrus (Fig. 3A). Stinkbugs were predominantly captured on lured yellow traps near tomato (Fig. 3B). The vegetable pest Plautia affinis (Dallas) (30 specimens) dominated samples, with a single

Dictyotus caenosus (Westwood) on a citrus sentinel trap (no lure). Plautia affinis were significantly attracted to the BMSB lure, with eight attracted to just the BMSB lure and 17 to the combination trap (Fig. $3 B$ ). Interestingly though, no stink bugs were captured with the ACP lure alone. Without any lure, only two P. affinis were recorded (Fig. 3B). Capture rates also decreased with time, with 15, 10, 5, 1 stink bugs caught in weeks 1 to 4 , respectively (Fig. 3C).

\section{Discussion}

Lures significantly increase trap efficacy for targeted insect species. The commercial lures we utilized increase capture of Asian citrus psyllid by 3-4 times (Czokajlo et al. 2015), and brown marmorated stink bug by $120+$ times (Weber et al., 2019). Lures can, however, have consequences on the capture rates of non-target taxa, and these impacts are not always predicted by taxonomic boundaries. For example, lures of the Noctuidae moth Helicoverpa armigera (Hübner) attract significantly more non-target moths, bees and ladybird beetles to traps (Spears et al., 2016). We found that tomato potato psyllid (TPP) was repelled by both ACP and BMSB lures, despite TPP and ACP both belonging to the superfamily Psylloidea. Psyllids representing the families Aphalaridae and Psyllidae were also repelled by ACP lures. Asian citrus psyllid belongs to the family Liviidae and is not represented by any known species in Western Australia, so the intrafamilial efficacy of the ACP lure remains unknown. Attraction or avoidance to lures corresponds to the chemicals used. The chemicals in ACP lures are a mixture of organic volatiles present in new flushes of citrus host plants, namely aphla-phellandrene, beta-phellandrene, beta-caryophyllene, gamma-terpinene, ocimene and terpineol (Setamou, 2018). As the chemicals originate from citrus, it follows that the lure should attract insects that feed on citrus, or other plants that produce similar organic volatiles, regardless of taxonomic identity. In our experiment, the only group attracted to the ACP lure were 'other triozids', which was driven predominantly by lilli pilly psyllid Trioza adventicia Tuthill, an introduced species from eastern Australia that feeds on Syzygium species (Francesco Martoni, Submitted 2021). The host plant families of T. adventicia and ACP are different (Myrtaceae and Rutaceae, respectively), but we surmise that the plant volatiles in the ACP lures must feature similar volatiles to those of Syzygium to attract the lilli pilly psyllid. Indeed, ACP lures include clove oil (Setamou, 2018) which originates from Syzygium (Cortés-Rojas et al., 2014), likely explaining the ACP lure attraction for T. adventicia. 
Furthermore, clove oil produces strong avoidance behaviour in TPP (Diaz-Montano \& Trumble, 2013), illuminating why TPP may have been repelled by ACP lures.

Instead of plant volatiles, lures may be based on insect pheromones, which will have an even more unpredictable effect on bycatch. For example, the $\mathrm{H}$. armigera lures mentioned above are based on pheromones, but can significantly increase ladybird beetle, bee and nontarget moth captures by $23 \%$, $110 \%$ and $>2,000 \%$, respectively (Spears et al. 2016). BMSB lures are pheromone lures and, while TPP was significantly repelled by the BMSB lure, psyllids other than TPP were attracted to BMSB lures, despite BMSB and psyllids belonging to different taxonomic suborders of true bugs (Heteroptera versus Sternorrhyncha). Delving into our psyllid data, high capture rates of a diverse composition of different species, mainly native Acizzia species, often dictated the pattern. In many cases, however, Ctenarytaina longicauda Taylor appeared to be driving the association on BMSB lured traps at tomato, and on sticky traps at citrus. Ctenarytaina longicauda is another recent arrival in Western Australia from eastern Australia (Francesco Martoni, Submitted 2021) and although Lophostemon confertus (R.Br.) is the known host plant, in Perth $C$. longicauda can be found in high abundances feeding on citrus (M.Moir pers. obs.). Why $C$. longicauda was not attracted to ACP lures, which are derived from the plant volatiles of fresh citrus growth (Setamou, 2018), remains unknown.

In some cases, species-specific lures will attract an unintended species within the same family. We found that BMSB lures attracted the pest stinkbug Plautia affinis (Dallas), the only known species of Plautia to occur in southwest Western Australia. Plautia affinis is a likely introduction from eastern Australia as records in Western Australia prior to (Cassis \& Gross, 2002) are scarce, with (Froggatt, 1907) restricting species distribution to the state of New South Wales. The earliest specimens from Western Australia were collected by L.J. Newman in Geraldton (ICDB 2018), no date is listed, but would have been after his appointment as Government entomologist in 1918 and prior to his death in 1938. BMSB lures contain, in part as a pheromone synergist for BMSB, the pheromone of Plautia stali Scott (methyl (2E,4E,6Z)-2,4,6decatrienoate), which is a sympatric species with BMSB in Asia (SUGIE et al., 1996). This component of the BMSB lures likely attracted $P$. affinis in our study, and other surveillance around Australia (Western Australia, M. Moir unpublished data; (Horwood et al., 2019). Moreover, despite the diversity of native pentatomids in Western Australia (approximately 137 described species; (Cassis \& Gross, 2002) lack of captures suggest that other species weren't attracted to the lures or sticky traps. Few stinkbugs are attracted to BMSB lures elsewhere, such as the pest Acrosternum hilare (Say) (Aldrich et al., 2009), and Euschistus servus (Say) (Cottrell et al., 2020) in the United States, but such examples are uncommon with most stinkbugs relatively lure specific (Tillman et al., 2010).

We found that combining lures will not counteract one another, nor will they have a cumulative impact on species examined here, supporting similar results for lures on BMSB and pest wood-boring beetles (Cerambycidae and Scolytinae: Curculionidae) (Chase et al., 2018), as well as Lepidoptera lures (Brockerhoff et al., 2013). For example, $P$. affinis was attracted to BMSB lures whether they were in combination with ACP lures or not, and although TPP was repelled by both lure types, combinations of these lures did not increase repellancy significantly. Unsurprisingly, we found that over time lure 
effectiveness declined as the chemical degrades, which has been an identified issue for lure longevity (Suckling, 2000); (Cottrell et al., 2020). The impact of the lures were most prominent for all taxa in the first two weeks, after which TPP was the only insect still detecting and avoiding BMSB lures.

While lures affected non-target insect capture in unpredictable ways, colour had a more consistent effect on Psylloidea. Yellow sticky traps are commonly used in surveillance as they have been found more effective at capturing Psylloidea than other colours tested such as white and black (Hodge et al., 2019). Specialist behavioural and anatomical studies have, however, indicated that Psylloidea have very good 'colour vision' (Farnier et al., 2015) and different species may prefer different colour spectrums (Farnier et al., 2014); Czokajlo et al. 2015). Despite this, we found that yellow-green ACP traps consistently attracted more Psylloidea, including TPP, other Triozidae, Psyllidae and Aphalaridae, than standard yellow traps. Conversely, stinkbugs were not attracted to either trap colour. Although our study had very low numbers of stinkbugs, this result is supported by (Cottrell et al., 2020) who found that BMSB and other stinkbugs are not significantly influenced by trap colour.

Our results provide evidence that olfactory cues are clearly more species-specific than colour for both Psylloidea and Pentatomoidea. This is unsurprising given that previous studies have shown the high sensitivity of olfactory cues, particularly for Psylloidea. For example, apples infected with apple proliferation phytoplasma (Phytoplasma mali) are more attractive to the vector summer apple psylla, thus facilitating the phytoplasma's spread (Mayer et al., 2008). Likewise, citrus infected with Ca. Liberibacter asiaticus attracts the vector, Asian citrus psyllid (Mann et al., 2012), and tomatoes infected with Ca. Liberibacter solanacearum attract uninfected TPP, while infected TPP prefer uninfected plants (Mas et al., 2014). TPP may be particularly sensitive to aromas as it is repelled not only by ACP and BMSB lures, as examined here, but also by essential oils of cedar wood, lime, savory, thyme, tea tree ((Diaz-Montano \& Trumble, 2013), garlic (Wright et al., 2013a), and different sulphur applications (DiazMontano \& Trumble, 2013); (Wright et al., 2013b).

\section{Conclusion}

Surveillance for plant pests is conducted to define the pest status of an area, improve the likelihood of early detection and monitor pest prevalence. The data collected from surveillance can help establish pestfree areas and streamline the trade of plants and plant products. While biosecurity agencies attempt to survey for many taxa with fewer resources, experimentally determining trap efficacy prior to initiating surveillance avoids squandering resources in the long-term. While attempting to incorporate additional exotic species into the surveillance for the bacterium CLso (vectored by TPP), we found that ACP and BMSB lures could not be used on traps intended to target TPP, but that 'green' ACP sticky traps were more effective at capturing TPP and other Psylloidea than yellow traps, and could confer a more effective multi-species approach. Our study demonstrates that, when planning multi-taxa surveillance or monitoring programs, lures must first be tested on both the target and non-target insect taxa to determine trap efficacy as the consequences for species catch can be unpredictable. 


\section{Declarations}

\section{Acknowledgements}

Rohan Burgess (Plant Health Australia) donated the ACP lures and yellow-green ACP sticky traps. We are indebted to all 104 adopt-a-trappers for volunteering their backyards and time for the biosecurity of Western Australia. Heidi Jackson, Cassandra Giorgi, Shannon Holler and Sharon Zuiddam are thanked for their assistance with data entry, support and/or trap examinations. Brenda Coutts and Rohan Prince are thanked for their managerial support of this work.

\section{Author Contribution Statement}

MM conceived, RM \& MM designed, MM obtained funding, DT, MM \& CF conducted the trials, CF \& MM identified insects and databased results, LC analysed data while MM \& LC interpreted it, LC \& MM constructed figures, MM, LC \& CF wrote manuscript with input from all authors, all authors read and approved the manuscript.

Funding This project was funded by Hort Innovation using the nursery, potato (fresh), potato (processing) and vegetable industry research and development levies, and contributions from the Australian Government. Hort Innovation is the grower-owned, not-for-profit research and development corporation for Australian horticulture.

Conflict of interest The authors declare that they have no conflict of interest.

Consent for publication Not applicable.

Consent to participate All Adopt-a-trappers consented to participate when contacted

Code availability Not applicable.

Availability of data and material All data generated or analyzed during this study are included in this published article and its supplementary information file.

Ethical approval According to Western Australian law, no ethical approval is required for work with invertebrates.

\section{References}

1. Aldrich JR, Khrimian A, Chen X, Camp MJ (2009) Semiochemically Based Monitoring of the Invasion of the Brown Marmorated Stink Bug and Unexpected Attraction of the Native Green Stink Bug (Heteroptera: Pentatomidae) in Maryland. Florida Entomologist 92(3):483-491. https://doi.org/10.1653/024.092.0310 489.

2. Antolinez CA, Fereres A, Moreno A (2017) Risk assessment of 'Candidatus Liberibacter solanacearum' transmission by the psyllids Bactericera trigonica and B. tremblayi from Apiaceae 
crops to potato. Sci Rep 7(1):45534. https://doi.org/10.1038/srep45534

3. Baroffio C, Sigsgaard L, Ahrenfeldt E, Borg-Karlson A-K, Bruun S, Cross J, Fountain M, Hall D, Mozuraitis R, Ralle B (2018) Combining plant volatiles and pheromones to catch two insect pests in the same trap: examples from two berry crops. Crop Prot 109:1-8

4. Brockerhoff EG, Suckling DM, Roques A, Jactel H, Branco M, Twidle AM, Mastro VC, Kimberley MO (2013) Improving the Efficiency of Lepidopteran Pest Detection and Surveillance: Constraints and Opportunities for Multiple-Species Trapping. J Chem Ecol 39(1):50-58. https://doi.org/10.1007/s10886-012-0223-6

5. Burckhardt D (1994) Psylloid pests of temperate and subtropical crop and ornamental plants (Hemiptera, Psylloidea): A review. Trends in Agricultural Sciences Entomology 2:173-186

6. Burckhardt D, Freuler J (2000) Jumping plant-lice (Hemiptera, Psylloidea) from sticky traps in carrot fields in Valais, Switzerland. Mitteilungen der Schweizerischen Entomologischen Gesellschaft 73(3/4):191-209

7. Butler CD, Trumble JT (2012) The potato psyllid, Bactericera cockerelli (Sulc)(Hemiptera: Triozidae): life history, relationship to plant diseases, and management strategies. Terrestrial Arthropod Reviews 5(2):87-111

8. CABI (2021) Bactericera cockerelli (tomato/potato psyllid) datasheet. https://www.cabi.org/isc/datasheet/45643\#tosummaryOfInvasiveness Assessed 3 April 2021

9. Cassis G, Gross GF (2002) Hemiptera: Heteroptera (Pentatomomorpha), vol 27. CSIRO PUBLISHING

10. Catling H (1970) Distribution of the psyllid vectors of citrus greening disease, with notes on the biology and bionomics of Diaphorina citri. FAO Plant Prot Bull 18(1):8-15

11. Chase KD, Stringer LD, Butler RC, Liebhold AM, Miller DR, Shearer PW, Brockerhoff EG (2018) MultipleLure Surveillance Trapping for Ips Bark Beetles, Monochamus Longhorn Beetles, and Halyomorpha halys (Hemiptera: Pentatomidae). J Econ Entomol 111(5):2255-2263. https://doi.org/10.1093/jee/toy190

12. Colunga-Garcia M, Haack R, Magarey R, Borchert D (2013) Understanding trade pathways to target biosecurity surveillance. NeoBiota, 18, 103

13. Cope RC, Ross JV, Wittmann TA, Watts MJ, Cassey P (2019) Predicting the Risk of Biological Invasions Using Environmental Similarity and Transport Network Connectedness. Risk Anal 39(1):35-53. https://doi.org/https://doi.org/10.1111/risa.12870

14. Cortés-Rojas DF, de Souza CRF, Oliveira WP (2014) Clove (Syzygium aromaticum): a precious spice. Asian Pacific journal of tropical biomedicine 4(2):90-96

15. Cottrell TE, Balusu RR, Vinson E, Wilkins B, Fadamiro HY, Tillman PG (2020) Effect of Trap Color and Residual Attraction of a Pheromone Lure for Monitoring Stink Bugs (Hemiptera: Pentatomidae). Journal of Entomological Science 55(4):437-447. https://doi.org/10.18474/0749-8004-55.4.437

16. Czokajlo D, Stelinski L, Godfrey K, Setamou M (2015) Novel attractant and trap for more sensitive ACP monitoring and detection. Citrograph 6(2):64-69 
17. Department of Agriculture and Water Resources (2017) Detection of Bactericera cockerelli (Tomatopotato psyllid) in Western Australia. Canberra. Available:

https://www.ippc.int/en/countries/australia/pestreports/2017/02/detection-of-bactericera-cockerellitomato-potato-psyllid-in-western-australia/

18. Diaz-Montano J, Trumble JT (2013) Behavioral responses of the potato psyllid (Hemiptera:

Triozidae) to volatiles from dimethyl disulfide and plant essential oils. Journal of Insect Behavior 26(3):336-351

19. European Food Safety Authority (2012) A framework to substantiate absence of disease: the risk based estimate of system sensitivity tool (RiBESS) using data collated according to the EFSA Standard Sample Description - An example on Echinococcus multilocularis. EN-366. 44 pp. Available online:

20. European Food Safety Authority, Lázaro E, Parnell S, Vicent Civera A, Schans J, Schenk M, Cortiñas Abrahantes J, Zancanaro G, Vos S (2020) General guidelines for statistically sound and risk-based surveys of plant pests. EFSA supporting publication 2020:EN-1919. 65 pp. doi:10.2903/sp.efsa.2020.EN-1919

21. Farnier K, Dyer AG, Steinbauer MJ (2014) Related but not alike: not all Hemiptera are attracted to yellow [Original Research]. Frontiers in Ecology Evolution, 2(67). https://doi.org/10.3389/fevo.2014.00067

22. Farnier K, Dyer AG, Taylor GS, Peters RA, Steinbauer MJ (2015) Visual acuity trade-offs and microhabitat-driven adaptation of searching behaviour in psyllids (Hemiptera: Psylloidea: Aphalaridae). J Exp Biol 218(10):1564-1571. https://doi.org/10.1242/jeb.120808

23. Francesco Martoni JSB, Melinda L, Moir MJ, Steinbauer, Gary S, Taylor. (Submitted 2021). An annotated checklist with key to the genera of Australian psyllids (Hemiptera: Sternorrhyncha: Psylloidea). Zootaxa

24. Froggatt WW (1907) Australian insects. Australian Insects.

25. Greenway GA, Rondon S (2018) Economic impacts of zebra chip in Idaho, Oregon, and Washington. Am J Potato Res 95(4):362-367

26. Hall DG, Sétamou M, Mizell III, R. F (2010) A comparison of sticky traps for monitoring Asian citrus psyllid (Diaphorina citri Kuwayama). Crop Prot 29(11):1341-1346

27. Hoch G, Connell J, Roques A (2020) Testing multi-lure traps for surveillance of native and alien longhorn beetles (Coleoptera, Cerambycidae) at ports of entry and in forests in Austria. Management of Biological Invasions 11(4):677

28. Hodge S, Bennett J, Merfield CN, Hofmann RW (2019) Effects of sticky trap colour, UV illumination and within-trap variation on tomato potato psyllid captures in glasshouses. New Zealand Journal of Crop Horticultural Science 47(1):48-62. https://doi.org/10.1080/01140671.2018.1508043

29. Horwood M, Milnes JM, Cooper WR (2019) Brown marmorated stink bug, Halyomorpha halys (Hemiptera: Pentatomidae), detections in Western Sydney, New South Wales, Australia. Austral Entomology 58(4):857-865. https://doi.org/https://doi.org/10.1111/aen.12421 
30. ICDB (2018) Western Australian Agriculture Authority, 2013-2018 Available here https://www.agric.wa.gov.au/apex/eds/f?p=50000:1:31253822433492::NO, Accessed 21st April 2021

31. Mann RS, Ali JG, Hermann SL, Tiwari S, Pelz-Stelinski KS, Alborn HT, Stelinski LL (2012) Induced release of a plant-defense volatile 'deceptively'attracts insect vectors to plants infected with a bacterial pathogen. PLoS pathogens 8(3):e1002610

32. Mansfield S, McNeill MR, Aalders LT, Bell NL, Kean JM, Barratt BI, Boyd-Wilson K, Teulon DA (2019) The value of sentinel plants for risk assessment and surveillance to support biosecurity. NeoBiota, 48,1

33. Mas F, Vereijssen J, Suckling DM (2014) Influence of the Pathogen Candidatus Liberibacter Solanacearum on Tomato Host Plant Volatiles and Psyllid Vector Settlement. J Chem Ecol 40(11):1197-1202. https://doi.org/10.1007/s10886-014-0518-x

34. Mayer CJ, Vilcinskas A, Gross J (2008) Phytopathogen lures its insect vector by altering host plant odor. J Chem Ecol 34(8):1045-1049

35. Meurisse N, Rassati D, Hurley BP, Brockerhoff EG, Haack RA (2019) Common pathways by which non-native forest insects move internationally and domestically. J Pest Sci 92(1):13-27

36. Miñarro M, Somoano A, Moreno A, García RR (2016) Candidate insect vectors of apple proliferation in Northwest Spain. SpringerPlus 5(1):1240. https://doi.org/10.1186/s40064-016-2907-9

37. Munyaneza J, Crosslin J, Upton J (2007) Association of Bactericera cockerelli (Homoptera:

Psyllidae) with "zebra chip," a new potato disease in southwestern United States and Mexico. J Econ Entomol 100(3):656-663

38. Munyaneza J, Lemmetty A, Nissinen A, Sengoda V, Fisher T (2011) Molecular detection of aster yellows phytoplasma and" Candidatus Liberibacter Solanacearum" in carrots affected by the psyllid Trioza apicalis (Hemiptera: Triozidae) in Finland. Journal of Plant Pathology, 697-700

39. Seebens H, Blackburn TM, Dyer EE, Genovesi P, Hulme PE, Jeschke JM, Pagad S, Pyšek P, Winter M, Arianoutsou M (2017) No saturation in the accumulation of alien species worldwide. Nature communications 8(1):1-9

40. Setamou M, Czokajlo D, Saldana R (2018) Insect Attractants. USA Patent No

41. Spears LR, Looney C, Ikerd H, Koch JB, Griswold T, Strange JP, Ramirez RA (2016) Pheromone Lure and Trap Color Affects Bycatch in Agricultural Landscapes of Utah. Environ Entomol 45(4):10091016. https://doi.org/10.1093/ee/nvw085

42. Stringer LD, Soopaya R, Butler RC, Vargas RI, Souder SK, Jessup AJ, Woods B, Cook PJ, Suckling DM (2019) Effect of Lure Combination on Fruit Fly Surveillance Sensitivity. Sci Rep 9(1):2653. https://doi.org/10.1038/s41598-018-37487-6

43. Suckling D (2000) Issues affecting the use of pheromones and other semiochemicals in orchards. Crop Prot 19(8-10):677-683

44. SUGIE H, KAWASAKI YOSHIDA,M, MoRIYA KNOGUCHI,H, FUKUDA STAKAGI,K, YAMANAKA HFUJIIE,A, M., \& OHIRA Y (1996) Identification of the aggregation pheromone of the brown-winged green bug, 
Plautia stali Scott (Heteroptera: Pentatomidae). Appl Entomol Zool 31(3):427-431

45. Teulon D, Workman P, Thomas K, Nielsen M (2009) Bactericera cockerelli incursion dispersal and current distribution on vegetable crops in New Zealand. New Zealand Plant Protection 62:136-144

46. Thomas DB, Holler TC, Heath RR, Salinas EJ, Moses AL (2001) Trap-lure combinations for surveillance of Anastrepha fruit flies (Diptera: Tephritidae). Florida Entomologist, 344-344

47. Thomas K, Jones D, Kumarasinghe L, Richmond J, Gill G, Bullians M (2011) Investigation into the entry pathway for tomato potato psyllid Bactericera cockerelli. New Zealand Plant Protection 64:259-268

48. Tillman PG, Aldrich JR, Khrimian A, Cottrell TE (2010) Pheromone Attraction and Cross-Attraction of Nezara, Acrosternum, and Euschistus spp. Stink Bugs (Heteroptera: Pentatomidae) in the Field. Environ Entomol 39(2):610-617. https://doi.org/10.1603/en09114

49. Walker PW, Allen GR, Tegg RS, White LR, Wilson CR (2015) The tomato potato psyllid, Bactericera cockerelli (Šulc, 1909) (Hemiptera: Triozidae): a review of the threat of the psyllid to Australian solanaceous crop industries and surveillance for incursions in potato crops. Austral Entomology 54(3):339-349. https://doi.org/https://doi.org/10.1111/aen.12129

50. Weber DC, Morrison WR, Khrimian III, Rice A, Short KB, Herlihy BD, M. V., \& Leskey TC (2019) Attractiveness of Pheromone Components With and Without the Synergist, Methyl (2E,4E,6Z)-2,4,6Decatrienoate, to Brown Marmorated Stink Bug (Hemiptera: Pentatomidae). J Econ Entomol 113(2):712-719. https://doi.org/10.1093/jee/toz312

51. Wong JCH, Mitchell RF, Striman BL, Millar JG, Hanks LM (2012) Blending Synthetic Pheromones of Cerambycid Beetles to Develop Trap Lures That Simultaneously Attract Multiple Species. J Econ Entomol 105(3):906-915. https://doi.org/10.1603/ec11434

52. Wright P, Walker G, Hedderley D (2013a) Effects of garlic oil on tomatopotato psyllid. New Zealand Plant Protection 66:387-387

53. Wright PJ, Walker GP, Hedderley DI (2013b) Effects of sulphur on control of tomato potato psyllid in potato. New Zealand Plant Protection 66(0):386-386. https://doi.org/10.30843/nzpp.2013.66.5701

54. Yen AL, Madge DG, Berry NA, Yen JDL (2013) Evaluating the effectiveness of five sampling methods for detection of the tomato potato psyllid, Bactericera cockerelli (Šulc) (Hemiptera: Psylloidea: Triozidae). Australian Journal of Entomology 52(2):168-174. https://doi.org/https://doi.org/10.1111/aen.12006

55. Zanardi OZ, Volpe HXL, Luvizotto RAG, Magnani RF, Gonzalez F, Calvo C, Oehlschlager CA, Lehan BJ, Esperança V, Delfino JY, de Freitas R, de Carvalho RI, Mulinari TA, Miranda MP, Bento JMS, Leal WS (2019) Laboratory and field evaluation of acetic acid-based lures for male Asian citrus psyllid, Diaphorina citri. Sci Rep 9(1):12920. https://doi.org/10.1038/s41598-019-49469-3

\section{Supplementary}

Supplementary material Appendix 1 is not available with this version. 


\section{Figures}

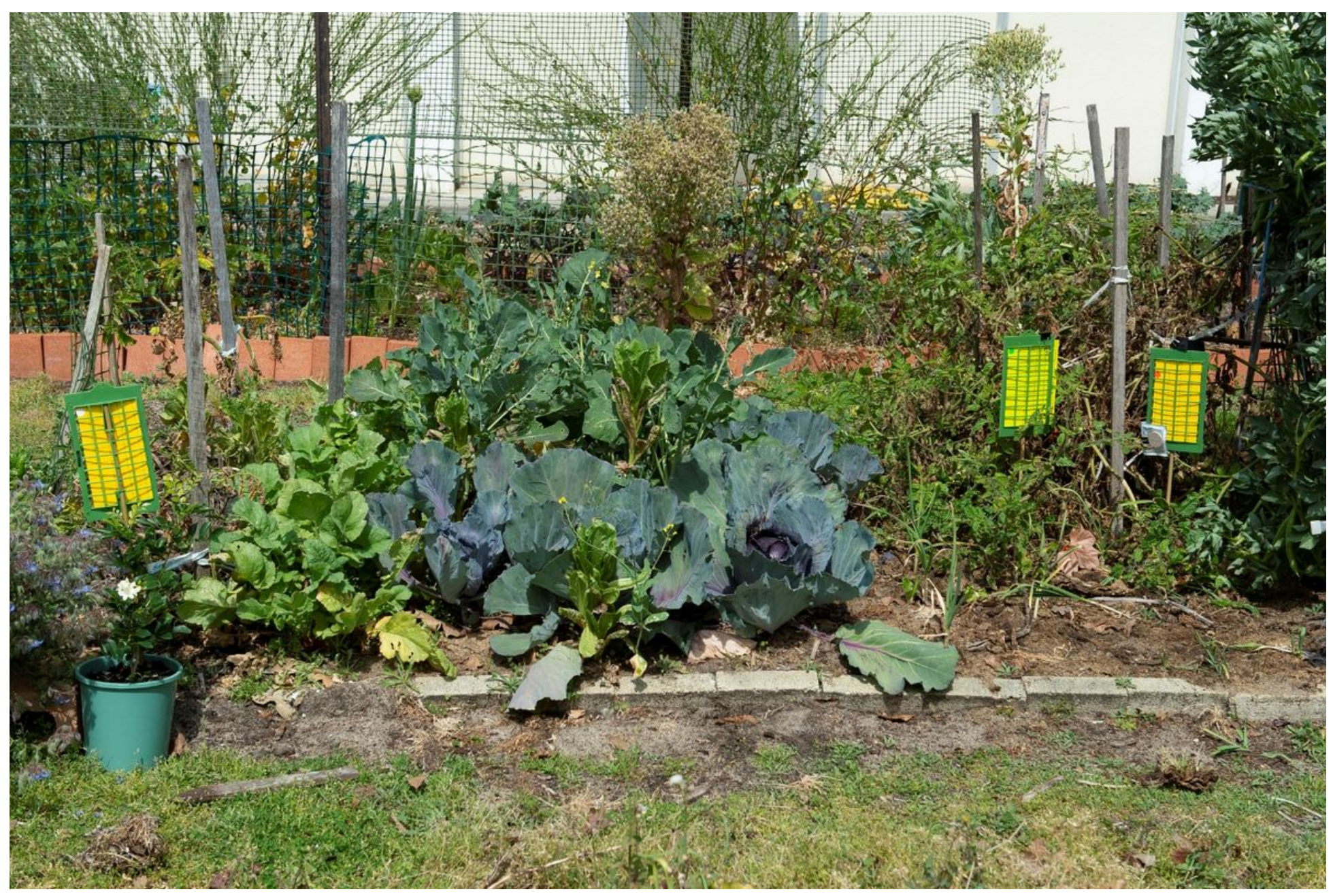

\section{Figure 1}

trap design set up showing tomato plant with both yellow sticky trap with two lures attached (far right), and the green sticky trap (middle), and a Murraya sentinel plant with a yellow sticky trap (left). 

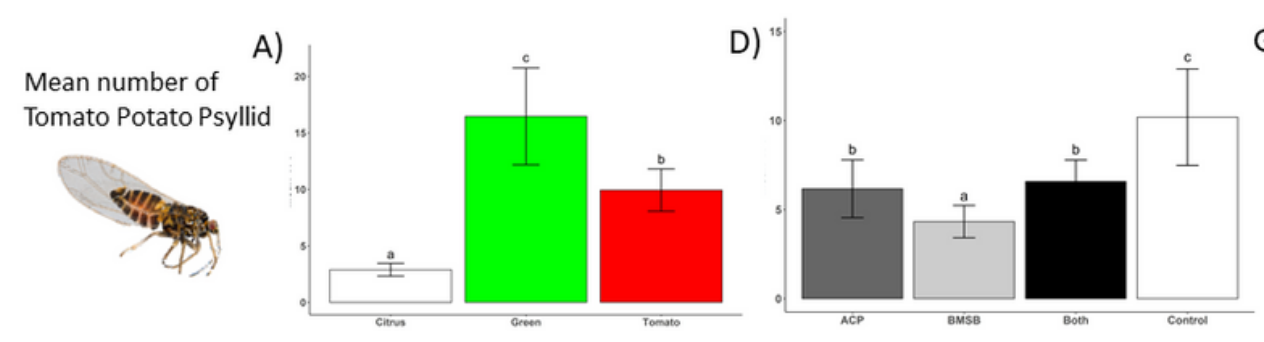

G)
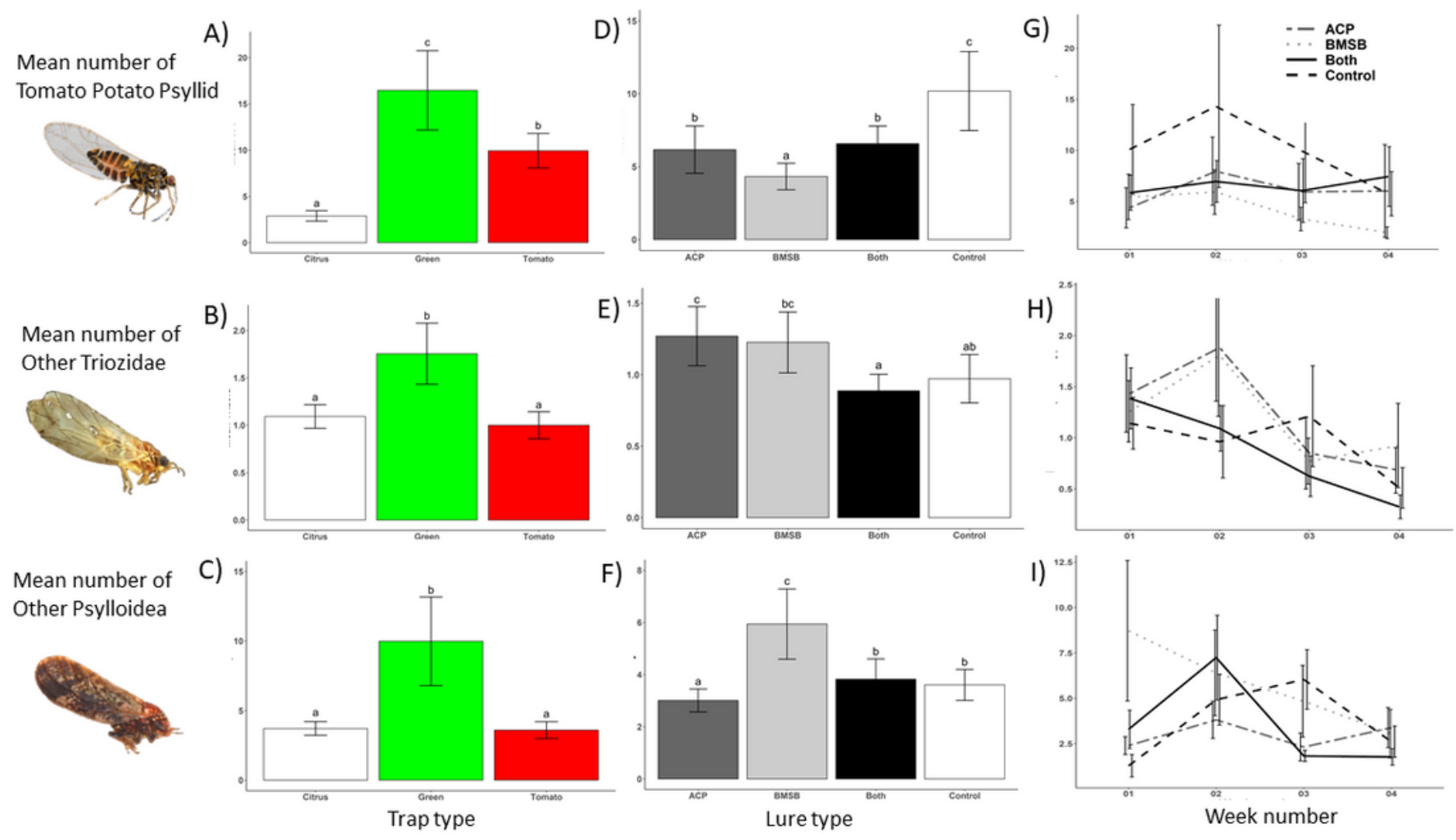

\section{Figure 2}

The effect of trap colour, sentinel plant, and lures on number of different Psylloidea individuals. Specifically, A)-C) individuals captured on yellow sticky traps near citrus (white bar), green traps (green bar) and yellow sticky traps near tomato (red bar); D)-F) individuals captured on tomato yellow traps with different lure combinations of Asian citrus psyllid (ACP) lures, brown marmorated stink bug (BMSB) lures, both ACP and BMSB lures, and control (no lures); G)-I) the interaction of lure against time. Letters over bars indicate significant differences at $P<0.05$. The images are from top to bottom: Bactericera cockerelli (Triozidae) (C Pia Scanlon, Western Australian Agricultural Authority 2020; Trioza barrettae (Triozidae) @ M.L. Moir; and Acizzia sp. (Psyllidae) @ M.L. Moir. 

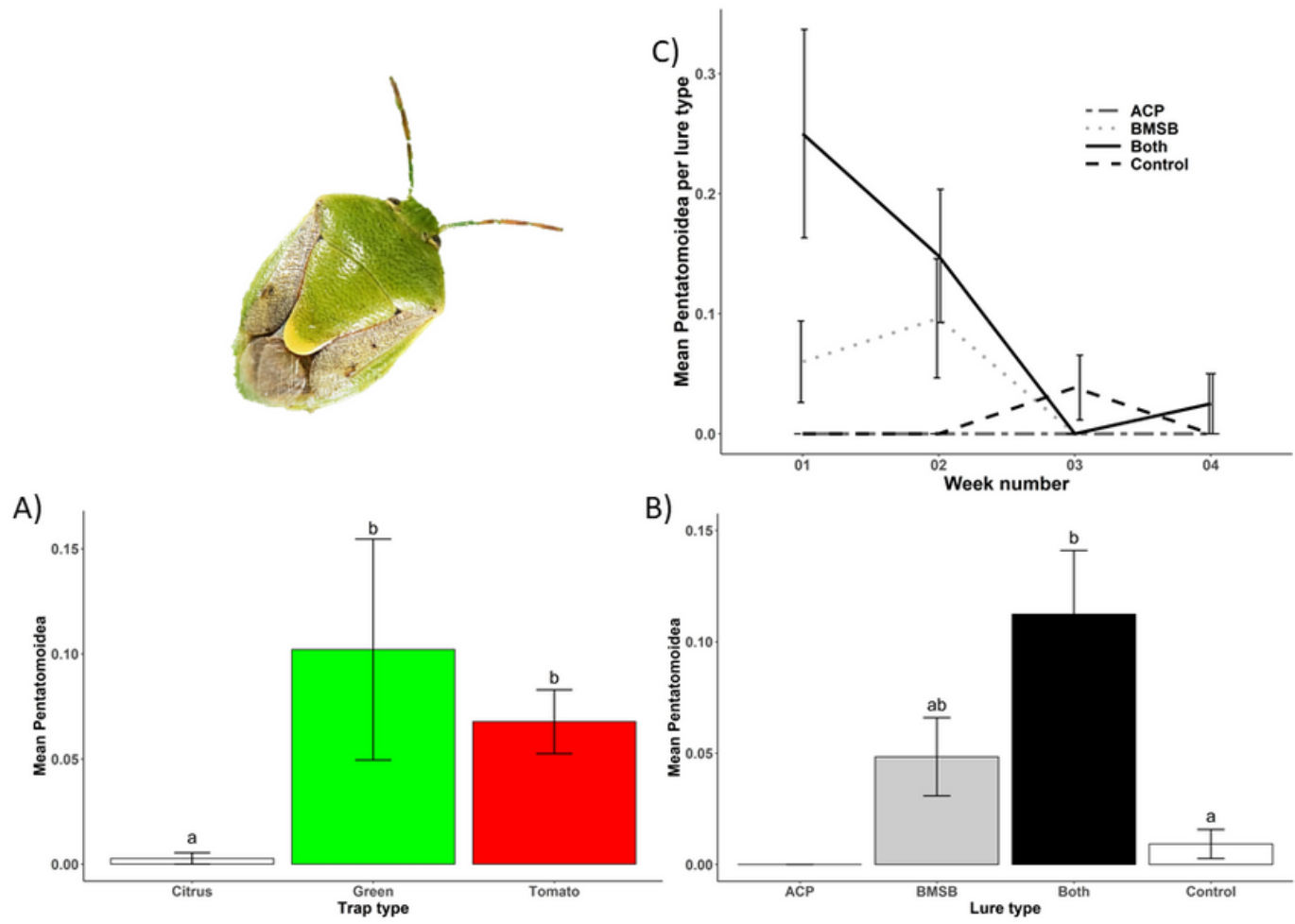

\section{Figure 3}

The effect of trap colour, sentinel plant, and lures on number of different Pentatomoidea stinkbugs. Specifically, A) individuals captured on yellow sticky traps near citrus (white bar), green traps (green bar) and yellow sticky traps near tomato (red bar); B) individuals captured on tomato yellow traps with different lure combinations of Asian citrus psyllid (ACP) lures, brown marmorated stink bug (BMSB) lures, both ACP and BMSB lures, and control (no lures); $C$ ) the interaction of lure against time. Letters over bars indicate significant differences at $\mathrm{P}<0.05$. The image is of the most dominant Pentatomoidea captured, Plautia affinis (Pentatomidae) @ ( Pia Scanlon, Western Australian Agricultural Authority 2020. 